\title{
REVIEW
}

\section{Epithelial injury induces an innate repair mechanism linked to cellular senescence and fibrosis involving IGF-binding protein-5}

\author{
Gordon J Allan, James Beattie and David J Flint \\ SIPBS, University of Strathclyde, Glasgow G1 1XW, UK \\ (Correspondence should be addressed to D J Flint; Email: david.flint@strath.ac.uk)
}

\begin{abstract}
Fibrosis is associated with epithelial repair. It involves the activation of fibroblasts, increased production of extracellular matrix proteins and transdifferentiation to contractile, myofibroblasts that aid in wound contraction. This provisional matrix plugs the injured epithelium and provides a scaffold for epithelial cell migration, involving an epithelial-mesenchymal transition (EMT). When epithelial injury involves blood loss, this leads to platelet activation, the production of several growth factors and an acute inflammatory response. Under normal circumstances, the epithelial barrier is repaired and the inflammatory response resolves. However, in fibrotic disease, the fibroblast response continues, resulting in unresolved wound healing. The fibrotic diseases range from scleroderma, where the problem may be restricted to the skin and where it is not life-threatening, through to systemic forms that can
\end{abstract}

manifest as, for example, idiopathic pulmonary fibrosis, in which death is inevitable within 3-5 years. Anti-inflammatory treatments have failed to ameliorate the disease condition and focus has instead turned to transforming growth factor- $\beta 1$ (TGFB1), since it induces many of the processes involved, including fibroblast activation and EMT. Most recently, however, a new player in this process has been described, IGF-binding protein-5 (IGFBP5). IGFBP5 has also been shown to induce similar effects to TGFB1, but, in addition, it is strongly implicated in the process of senescence which is now believed to be a significant factor in these diseases. We examine the evidence for this role of IGFBP5 and identify some of the therapeutic targets which might be used to ameliorate these diseases of unknown cause.

Journal of Endocrinology (2008) 199, 155-164

\section{Overview of the fibrotic response}

Excessive fibroblast activation can result in debilitating and even fatal diseases which progress rapidly from diagnosis. These include idiopathic pulmonary fibrosis (IPF) and systemic sclerosis $(\mathrm{SSc})$, the latter affecting multiple organs of the body. In its localized form within the skin, scleroderma has been termed 'the disease which turns people to stone' because of the appearance of the skin, which is thickened and lacks elasticity. This lack of elasticity is fatal in IPF which is a progressive lung disease characterized by lung scarring and abnormal gas exchange resulting from excessive collagen deposition (Gross \& Hunninghake 2001). The disease is rare in children, but prevalence increases from three to four per 100000 in young adults to over 200 per 100000 in the $75+$ age group (Garcia et al. 2007). This translates to around 90000 people diagnosed with IPF in the United States, with about 35000 new cases diagnosed each year (Raghu et al. 2006). IPF is always fatal, with no spontaneous remission and with a median lifespan after diagnosis of 3 years.
$\mathrm{SSc} /$ scleroderma involves excessive fibrosis of the skin and internal organs due to fibroblast proliferation and excessive production of extracellular matrix (ECM). The agents responsible for inducing fibrosis in SSc are still unknown, but the fibrotic changes lead to the destruction of normal structures in the skin and other organs with no effective treatments to halt its progression (Highland \& Silver 2005). Although survival in patients with SSc has steadily improved, it remains poor when compared with that in age- and sexmatched populations (Mayes et al. 2003). The rate of mortality due to renal failure in SSc has decreased with the use of angiotensin-converting enzyme inhibitors (Steen 2007) and mortality in SSc is now mainly due to pulmonary complications, which include interstitial lung disease and pulmonary arterial hypertension.

Since one of the pathologic features of SSc is the excessive deposition of collagen and fibronectin (Costner \& Jacobe 2000), it is not surprising that fibroblasts play an important role in the pathogenesis of this disease (LeRoy 1992, Kissin \& Korn 2002). The classic hallmarks of the fibrotic disease 
include activation of fibroblasts, with increased production of collagen and fibronectin, and transdifferentiation of fibroblasts into contractile myofibroblasts. A myofibroblast is defined as a spindle-shaped cell that is positive for vimentin and $\alpha$-smooth muscle actin ( $\alpha$-SMA) or vimentin alone (Eyden 2001, Willis et al. 2005). Skin tissue in individuals with SSc is characterized by the presence of $\alpha$-SMA-positive cells, and these myofibroblasts have been shown to persist in fibroblast cultures derived from individuals with SSc (Sappino et al. 1990, Kirk et al. 1995). The fibrotic response also involves increased production of several cytokines and growth factors, including transforming growth factor- $\beta 1$ (TGFB1) and connective tissue growth factor (CTGF). TGFB1 has been shown to stimulate fibroblast proliferation and the production of ECM components in vitro, making it a prime candidate as a causative factor (Takehara 2003, Leask \& Abraham 2004).

Although best characterized by excessive deposition of ECM, fibrotic diseases are also accompanied by an inflammatory response involving monocyte/macrophage activation, and thus attempts to control the progress of these diseases with anti-inflammatory therapies have been undertaken. However, the inability of immunosuppressive therapies to affect disease progression has led to the proposal that inflammation is a secondary component of the condition and such therapies are, at best, of limited value. This has led to recent re-evaluations of fibrosis and the development of two related hypotheses. In the first, it has been suggested that cycles of relatively superficial epithelial injury occur with such frequency that epithelial cell responses (typically epithelial cell proliferation and migration into the injured site) are insufficiently rapid. Consequently, a secondary response is required, involving activation, migration and transdifferentiation of mesenchymal fibroblasts. Excessive stimulation of this pathway leads to the development of fibroblastic/myofibroblastic foci with exaggerated accumulation of ECM (Fig. 1). Such a response has been likened to an abnormal, unresolved

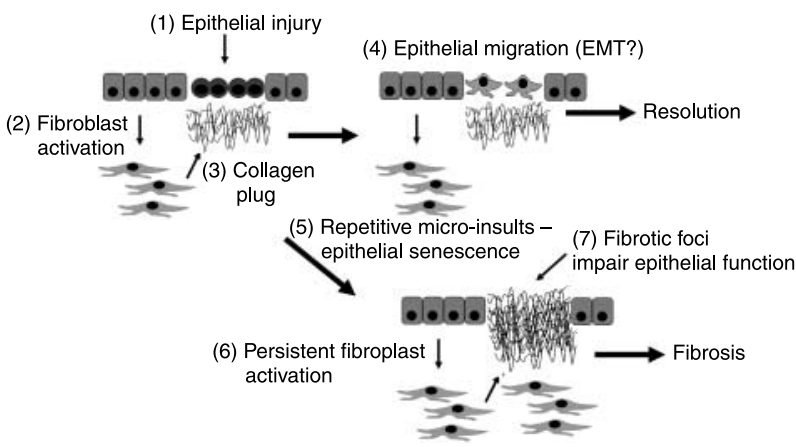

Figure 1 (1) Epithelial injury results in the release of factors that (2) activate fibroblasts resulting in the production of (3) collagen and fibronectin to plug the compromised epithelium. (4) Epithelial migration possibly involving EMT, repairs the epithelium leading to resolution. By contrast, (5) repeated micro-insults result in (6) persistent fibroblast activation and transdifferentiation into myofibroblasts and the (7) development of fibrotic foci. wound repair response (Selman \& Pardo 2006). In the second hypothesis, the mechanism has been linked to the process of senescence. In the normal response to injury, epithelial cells not only undergo an epithelial-mesenchymal transition (EMT) and migrate over the wound site, but also exhibit a burst of proliferation to replace lost cells. Most cells exhibit a finite ability to replicate (Hayflick's number, (Hayflick \& Moorhead 1961)), and thus it is proposed that repeated insults lead to focal areas where epithelial cells can no longer proliferate and, instead, enter a state of replicative senescence. At this stage, a fibroblast response is evoked as a compensatory mechanism that serves to plug the site of injury. This hypothesis is certainly consistent with the increasing prevalence of this disease as we age, and this link between the process of ageing and fibrosis is discussed in greater detail below.

\section{TGFB1 and fibrosis}

In terms of the mediators involved in driving fibrosis, much interest has been focussed on the major pro-fibrotic cytokine, TGFB1, which induces many of the central processes involved in fibrosis, including fibroblast to myofibroblast differentiation, ECM deposition and EMT, but without inducing inflammation (reviewed in (Scotton \& Chambers 2007)). A major step involved in the regulation of TGFB1 bioavailability involves the activation of a latent form of this cytokine by removal from its latency-associated peptide. Although there are numerous mechanisms by which latent TGFB may be activated in vitro, including direct cleavage by plasmin, activation by the $\alpha v \beta 6$ integrin has been shown to be important in models of a number of disease processes, including pulmonary and renal fibrosis (see (Jenkins et al. 2006)). It is not presently fully understood how the $\alpha_{v} \beta 6$ integrin activates latent TGFB but it is likely that the integrin needs to be activated itself, because tissue-specific overexpression of the $\beta 6$ integrin subunit, in the absence of injury, does not lead to TGFB activation or tissue fibrosis (see (Jenkins et al. 2006)).

\section{Insulin-like growth factor-binding protein 5 (IGFBP5) a novel player in fibrosis?}

Increased expression of IGFBP5 has also recently been described in fibrosis. Increased expression of IGFBP3 and IGFBP5 is evident in two human fibrotic disorders, SSc and IPF (Feghali \& Wright 1999, Pilewski et al. 2005). IGFBP5 mRNA and protein levels are also increased in vitro in primary fibroblasts cultured from disease-affected skin of patients with $\mathrm{SSc}$, compared with the skin from their healthy twins. IGFBP5 has been shown to be able to induce collagen and fibronectin production from fibroblasts and to induce fibroblast/myofibroblast transdifferentiation in vitro and in vivo (Yasuoka et al. 2006a,b). Overexpression of IGFBP3 and 
IGFBP5 in primary human fibroblasts increased the expression of ECM components such as collagen and fibronectin (Pilewski et al. 2005). Finally, in vivo overexpression of IGFBP5, using replication-deficient adenovirus, induced skin fibrosis in mice which included increased thickness of the dermis and increased collagen bundle thickness (Yasuoka et al. 2006a) and pulmonary fibrosis (Yasuoka et al. 2006b). The development of dermal fibrosis was accompanied by augmented synthesis of collagen and fibronectin and an increase in the number of dermal fibroblasts expressing PCNA. Increased expression of vimentin and $\alpha$-SMA in dermal fibroblasts overexpressing IGFBP5 was also evident, suggesting that IGFBP5 induces the transition of fibroblasts into myofibroblastic cells. Taken together, these findings demonstrate that overexpression of IGFBP5 in skin induces activation of resident fibroblasts and their transformation into myofibroblasts, thus resulting in the fibrotic phenotype. These findings suggest that upregulated expression of IGFBP5 could be an initiating event in ECM production and the development of fibrosis. But what induces increased expression of IGFBP5?

\section{IGFBP5 secretion increases during epithelial cell death}

IGFBP5 expression increases dramatically in the involuting mammary gland and prostate when the secretory epithelium undergoes apoptosis (Guenette \& Tenniswood 1994, Flint et al. 2000) and, when expressed as a transgene in the mammary gland, IGFBP5 enhanced apoptotic events and impaired mammary development (Tonner et al. 2002). By contrast, apoptosis in the mammary gland is impaired in an IGFBP5 knockout mouse (Ning et al. 2007). IGFBP5 is also increased in the brain following ischaemia (O'Donnell et al. 2002) and in the cardiovascular system during atherosclerotic plaque formation (functions unknown) (Kim et al. 2007). These findings link processes evoked during epithelial injury/death with increased expression of IGFBP5. But which of the processes associated with fibrosis are initiated by IGFBP5 when it is upregulated?

The fibrotic response involves several key events: the initial injury to the epithelial barrier, EMT, epithelial senescence, fibroblast activation and a subsequent inflammatory response. Below we consider in greater detail, the evidence for a role of IGFBP5 in each of these aspects and also discuss possible signal transduction mechanisms involved in such actions of IGFBP5.

\section{IGFBP5 and EMT}

We have shown that IGFBP5 induces a phenotypic EMT in a human breast cancer cell line, MCF-7 (Fig. 2), and activates tissue plasminogen activator (tPA; Sorrell et al. 2006). The tPA plays a central role not only in fibrinolysis but also in activating several MMPs involved in cellular (a)

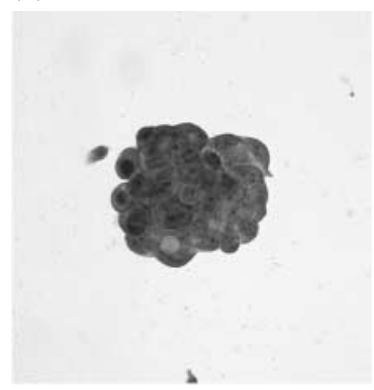

(b)

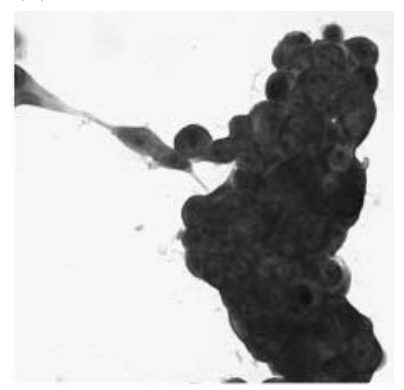

(c)

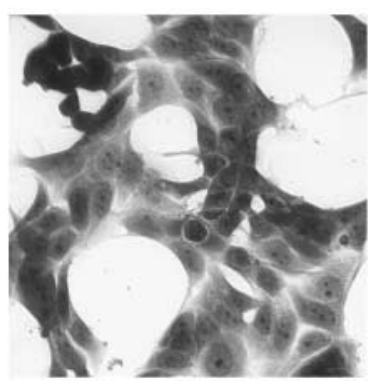

(d)

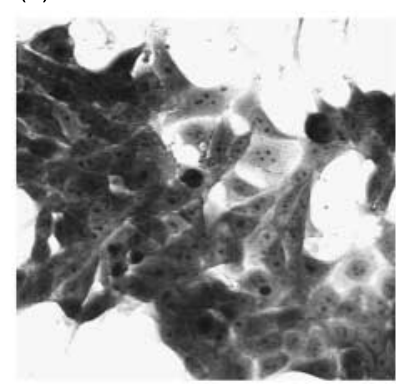

Figure 2 (a) MCF-7 epithelial cells form strong cell-cell contact and weak cell-substratum interactions in serum-free conditions. (b) IGF-1 induces cell migration and further cell adhesion resulting in larger epithelial structures. By contrast, IGFBP5, (c) alone or (d) in combination with IGF-1, induces a decrease in cell-cell adhesion and increased cell-substratum contact.

migration/invasion and in activating TGFB1. IGFBP5 has also been shown to interact with various molecules belonging to the matricellular 'family' of proteins (thrombospondins 1 and 2, osteopontin, SPARC and tenascin-C and $-\mathrm{X}$ ). These proteins are widely expressed in the foetus, but their expression is decreased in the adult unless activation occurs during processes such as wound healing or metastasis, where they are implicated in cellular adhesion and migration. Thus far, IGFBP5 has been shown to bind to osteopontin, thrombospondin-1 (Nam et al. 2000) and tenascin-C (Clemmons et al. 1995) although the functional significance of these interactions is unclear. These findings provide persuasive evidence for a role of IGFBP5 in EMT and associated cellular migration processes.

\section{IGFBP5 and senescence}

Senescence is the complex process of deterioration that occurs over the lifetime of an organism, resulting in progressive functional decline and eventual death. Cellular senescence is a phenomenon related to cellular stress where cells lose the ability to proliferate. Normal somatic cells, when cultured in vitro, have a finite ability to divide after which they enter a state of irreversible proliferative arrest, termed replicative senescence (Hayflick \& Moorhead 1961). Irreversible growth arrest is also 
induced in primary cells by the expression of activated oncogenes such as Ras (Serrano et al. 1997) or Raf (Zhu et al. 1998 ) or by the activation of tumour suppressor genes (Tyner et al. 2002, Jacobs \& de Lange 2004). Senescent cells display a characteristic enlarged, flattened morphology (Wagner et al. 2001), express senescence-associated $\beta$-galactosidase (Dimri et al. 1995), are resistant to proliferative stimuli (Park et al. 2000) and show altered gene expression (Smith \& Pereira-Smith 1996). Evidence implicating the tumour suppressors, p53, p16 and $\mathrm{pRB}$, as the common major effectors of cellular senescence in normal somatic cells has been published (Beausejour et al. 2003, Campisi 2005). Recently, pulmonary fibrosis has been linked to cellular senescence (Garcia et al. 2007). IGFBP5 expression has been reported to be upregulated in human dermal fibroblasts (Yoon et al. 2004) and endothelial cells (Hampel et al. 2006) during replicative senescence, further implicating IGFBP5 in this aspect of the fibrotic response. Knockdown of IGFBP5 in aged human umbilical vein endothelial cells (HUVECs) partially reversed the process of senescence, while exogenous IGFBP5 or overexpression of IGFBP5 induced premature senescence in HUVECs in vitro. This IGFBP5-induced senescence was associated with the induction of the tumour suppressor p53 (Kim et al. 2007).

In fact, the insulin/IGF signal transduction pathway is implicated in the ageing of many organisms, including nematodes and fruit flies, as well as mammals (Kenyon 2001, Longo \& Finch 2003). For example, IGF-1 has been shown to extend the in vitro replicative lifespan of satellite cells by modulating cell cycle regulatory molecules (Chakravarthy et al. 2000), whereas repression of insulin/IGF-1 signalling by the deletion of the growth hormone receptor (Shimokawa et al. 2002, 2003) or IGF-1R (Holzenberger et al. 2003, Holzenberger 2004) leads to an increased lifespan in vivo. The fact that IGFBPs can modulate the activity of IGF-1 adds further support to the idea that they play an important role in the ageing process.

\section{IGFBP5 and fibroblast activation}

As described earlier, there is increased an expression of IGFBP5 in fibrosis (Pilewski et al. 2005), IGFBP5 can induce collagen and fibronectin production from fibroblasts and induce fibroblast/myofibroblast transdifferentiation in vitro and in vivo (Yasuoka et al. 2006a,b). Overexpression of IGFBP5 in vitro and in vivo increases the expression of ECM components such as collagen and fibronectin and induces a fibrotic response (Pilewski et al. 2005, Yasuoka et al. 2006a,b). Induction of increased expression of vimentin and $\alpha$-SMA in dermal fibroblasts by IGFBP 5 also indicates that IGFBP 5 can stimulate transdifferentiation of fibroblasts into myofibroblasts.

In summary, there is evidence for a role of IGFBP5 in every aspect of the early responses present during the development of fibrosis: upregulation of IGFBP5 by epithelial injury, induction of EMT, induction of epithelial senescence and fibroblast activation. How IGFBP5 induces these effects at the cellular level is, however, still the subject of debate.

\section{Mechanisms of action of IGFBP5}

IGFBP5 is one of a family of six IGF-binding proteins, IGFBP1-6, that bind to IGFs with high affinity (see (Beattie et al. 2006) for review). IGFBPs are secreted by many cell types and have differential cell- and tissue-type-dependent expression patterns (Schneider et al. 2002). Binding of IGFs to IGFBPs can restrict access to the IGF1 receptor, resulting in the inhibitory effects of the IGFBPs on cell proliferation, differentiation and survival. In addition to the IGF-dependent activity of IGFBPs, IGF-independent actions of IGFBPs have also been reported (see (Beattie et al. 2006). Both of these potential mechanisms are discussed in greater detail below.

\section{Direct effects}

IGFBP5 has been shown to bind to an uncharacterized cell surface protein of $\sim 450 \mathrm{kDa}$ in osteoblasts (Andress 1998). However, it remains to be determined whether this is a receptor, as to date this receptor has not been characterized and no IGFBP5-stimulated intracellular signalling pathways have been consistently identified, although a link with ERK activation has been described (Amaar et al. 2005).

It also has been suggested that IGFBP5 encodes a potential nuclear localization sequence within its carboxy-terminus (Schedlich et al. 1998) and, after exogenous administration, IGFBP5 could be detected in the nucleus of human osteoblasts by immunocytochemistry (Mohan et al. 2002). Genetic screens using the yeast 2-hybrid assay with IGFBP5 as 'bait', and a cDNA expression library from U2 osteosarcoma cells as 'prey', have led to the identification of several putative IGFBP5 interacting proteins that are primarily expressed intracellularly (Mohan \& Baylink 2002). Amaar et al. (2002) demonstrated that IGFBP5 interacts with four-and-a-half LIM protein-2 and hypothesized that this interaction facilitates transport into the nucleus where the complex then modulates the transcription of genes involved in osteoblast proliferation and/or differentiation. Whether nuclear accumulation of IGFBP5 occurs in vivo under physiological conditions remains unknown, and the biological consequences remain to be characterized. It should be noted that the physiological role for nuclear localization of IGFBP5 is still the subject of debate (Jurgeit et al. 2007).

\section{Indirect actions of IGFBP5}

Influencing the actions of IGFs The most apparent indirect action of IGFBP5 is its binding to, and influencing the actions of, IGFs and this has been extensively documented (see (Beattie et al. 2006). IGFBPs can also interact with biomolecules other than IGFs, including ECM glycosaminoglycans (Arai et al. 1994), ECM proteins (Jones et al. 1993) and hydroxyapatite in bone (Campbell \& Andress 1997). These interactions can decrease the affinity of the IGF-IGFBP interaction, thereby serving to enhance the actions of IGFs. 
IGFBP3 and IGFBP5 also bind to the ECM, including type I collagen and fibronectin (Jones et al. 1993, Liu et al. 2003, Pilewski et al. 2005). Moreover, secreted IGFBPs can be proteolytically cleaved and degraded by several proteases identified to date (Nam et al. 1994, Firth \& Baxter 1995, Morales 1997) while IGFBP-binding partners such as fibronectin and other ECM components can protect IGFBPs from proteolytic degradation and thus prolong their bioavailability (Jones et al. 1993). However, there is no compelling evidence that IGFs inhibit fibrosis (and that IGFBP5 might inhibit this effect of IGFs) with the possible exception of cirrhosis of the liver (see below).

Extracellular actions of IGFBP5 This leaves an intriguing possibility in which IGFBP5 acts indirectly, extracellularly, in a fashion analogous to that of CTGF, which also, coincidentally, serves as a downstream mediator of the actions of TGFB1 (Nguyen \& Goldschmeding 2008). CTGF is structurally related to IGFBP5 and interacts with a number of extracellular molecules as its main mechanism of action, rather than exerting a direct interaction with a cell surface receptor. There are considerable similarities between IGFBP5 and members of the secreted cysteine-rich protein family that includes CTGF, CYR61 and Nov (CCN). Somewhat ironically, the CCN molecules were temporarily renamed IGFBP8-10 because of their structural relationship with the IGFBP family. We believe that IGFBP 5 may just as appropriately be considered a member of the CCN family. This family is unusual in that only Nov has an identified cell surface 'receptor', an integrin and, instead, these molecules are considered to exert their effects extracellularly by interaction with growth factors. For example, CTGF binds to VEGF (Inoki et al. 2002) and inhibits its actions and binds to, and enhances the actions of, TGFB1 (Abreu et al. 2002). Finally, IGFBP5 has been shown to interact with various molecules belonging to the matricellular 'family' of proteins. These proteins are widely expressed in the foetus but their expression is low in the adult unless activation occurs due to processes such as wound healing or metastasis, where they are implicated in cellular adhesion and migration. Thus far, IGFBP5 has been shown to bind to osteopontin, thrombospondin-1 (Nam et al. 2000) and tenascin-C (Clemmons et al. 1995) although the functional significance of these interactions is unclear.

More specifically, in relation to the development of fibrosis, there is a plausible mechanism of action of IGFBP5, which involves a role in the activation of TGFB1 via the coagulation cascade and involving integrin activation, in a fashion analogous to that of Nov.

Procoagulant signalling hypothesis There is compelling evidence that uncontrolled activation of the coagulation cascade following tissue injury contributes to the development of fibrosis in various disease settings, including fibrotic lung disease (reviewed in (Chambers 2008)). Present evidence suggests that the tissue factor-dependent extrinsic pathway is the predominant mechanism by which the coagulation cascade is locally activated in fibrotic lung disease. While, fibrin deposition might contribute to the pathophysiology of certain conditions, it has been shown that the cellular effects mediated via the activation of the high-affinity thrombin receptor, proteinase-activated receptor-1 (PAR-1), play a central role in influencing fibroproliferative responses following tissue injury. PAR-1 expression is highly elevated in the lungs of patients with IPF and scleroderma (Howell et al. 2001, Bogatkevich et al. 2005) and PAR-1 knockout mice are protected from developing bleomycin-induced lung fibrosis, as well as inflammation (Howell et al. 2005). Moreover, extensive in vitro studies have shown that activation of PAR-1 on numerous cell types may contribute to the development of fibrosis via the release and activation of potent pro-fibrotic mediators, including PDGF (Ohba et al. 1994), CTGF (Chambers et al. 2000) and chemokine (C-C motif) ligand 2 (CCL2; Deng et al. 2008). Of particular importance, a pivotal role for PAR-1 in the $\alpha_{v} \beta 6$ integrin-mediated activation of latent TGFB by the lung epithelium has recently been demonstrated in vitro and in vivo (Jenkins et al. 2006).

A link between IGFBP5, TGFB and the PAR-1 system is supported by our observations that mice expressing IGFBP5 as a transgene have elevated tissue concentrations of plasmin and that IGFBP 5 can activate tPA directly in cell-free systems generating increased amounts of plasmin (Sorrell et al. 2006). This effect of IGFBP5 on tPA is particularly interesting in relation to the procoagulant theory since several studies have shown that PAR$1 \mathrm{can}$ also be activated by plasmin (reviewed in (Chambers 2008)). Thus, IGFBP5 could activate TGFB1 directly via plasmin activation or indirectly via the activation of PAR-1 and $\alpha_{v} \beta 6$ integrin. Such studies are worthy of investigation.

\section{Cirrhosis of the liver: a possible role for IGFBP5 as an inhibitor of IGF-1?}

The liver is particularly susceptible to fibrosis, because it is exposed to a wide range of toxic insults. In addition, the liver is unusual in that hepatocytes produce large quantities of IGF-1 (they are the main source of IGF-1 in the circulation) but, unlike other epithelial cells, hepatocytes do not respond to IGF-1 because they possess few IGF-receptors (Sanz et al. 2005). Instead, hepatocyte-derived IGF-1 has been proposed to retain mesenchymal, stellate cells in a quiescent state, where they produce hepatocyte growth factor (HGF), an important survival factor for hepatocytes (Sanz et al. 2005), as part of the process of epithelial-mesenchymal crosstalk. For example, IGF-1 has recently been shown to inhibit collagen and TGFB1 production by stellate cells, while stimulating their synthesis of HGF (Kim et al. 2005, Lin et al. 2005). Overexpression of IGF-1 has also been shown to inhibit fibrosis and aid recovery from hepatic damage. Conversely, when hepatocytes are damaged in cirrhotic liver, circulating concentrations of IGF-1 decline providing a 'pro-fibrotic environment'. Thus, IGF-1 may play a dual role by suppressing the activation and conversion of stellate cells to myofibroblasts and simultaneously enhancing the epithelial 
repair processes via HGF production. Clearly, IGFBP production in this system could also modulate the effects of IGF-1 in an IGF-dependent fashion (Fig. 3).

\section{Fibrosis is also a component of cardiovascular disease}

Although a classic group of fibrotic diseases, including IPF, cirrhosis of the liver and renal fibrosis, are recognized for the major part fibrosis plays, it is now becoming apparent that the fibrotic response is also a significant component of other major diseases including, in particular, cardiovascular disease.

\section{Adventitial fibroblasts and cardiovascular disease}

While a central role for fibroblasts in diseases such as SSc and IPF is well accepted, it is now also becoming apparent that fibroblasts located in the adventitia, or outer coat of blood vessels, may play a similar role in driving hyperplasia in the intima, or inner coat of the vessel, in cardiovascular injury. Traditionally, vascular inflammation is considered to be an 'inside-out' response centred on the monocyte adhesion and lipid oxidation hypotheses. These mechanisms propose that the inflammatory response is initiated at the luminal surface. However, increasingly, evidence supports a new 'outside-in' hypothesis, in which inflammation is initiated in the adventitia and subsequently progresses inwards to the intima (Pagano \& Gutterman 2007). The outside-in hypothesis is supported by the fact that the adventitia is not simply a fibroblast layer but includes monocytes, macrophages and lymphocytes. Furthermore, there is a phenotypic switch of adventitial fibroblasts into migratory myofibroblasts, and increased angiogenesis of the vasa vasorum (the nutrient blood vessels that supply the walls of large arteries or veins). The adventitia has a localized humoral immune response in which $\mathrm{B}$ cells and $\mathrm{T}$ cells react to local antigen presentation by foam cells and antigen-presenting cells. This results in increased local expression of cytokines and an inflammatory response that progresses inwards towards the intima.

\section{Signalling events after balloon angioplasty}

Vessel injury is a common result of balloon angioplasty. The outside-in hypothesis is also supported by the observation that, after vessel injury, but before neointimal development occurs, the adventitia and perivascular tissue recruit neutrophils, macrophages and apoptotic cells (Scott et al. 1996, Best et al. 1999), which express numerous inflammatory molecules. For example, CCL2, a potent leukocyte chemoattractant, is highly expressed in myofibroblasts at the site of injury in the adventitia (Jabs et al. 2007). CCL2 is known to induce macrophage recruitment and activation. Furthermore, the cytokine CXCL2 is transiently upregulated in the adventitia at earlier time points than in the neointima, adding support to the idea of the inflammatory response arising in the adventitia and progressing towards the intima. Finally, as early as $2 \mathrm{~h}$ after injury from balloon angioplasty, neutrophils accumulate in the adventitia and perivascular tissues (Okamoto et al. 2001).

\section{Hypertension}

In models of hypertension, it has been shown that macrophage infiltration into the adventitia of large arteries

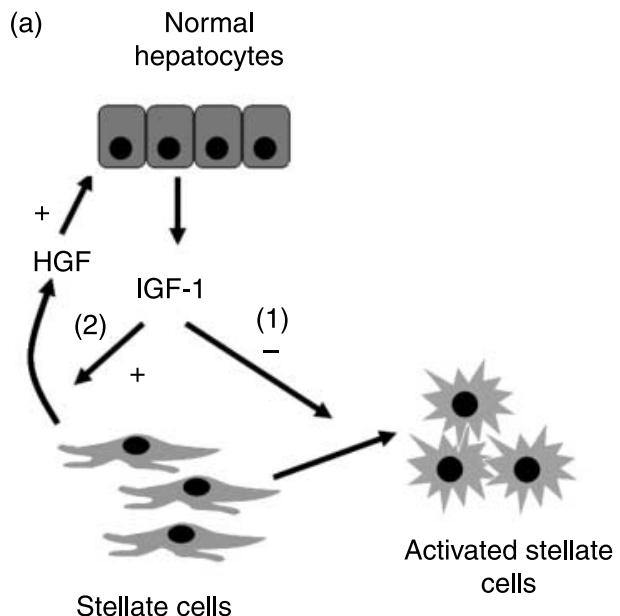

(b)

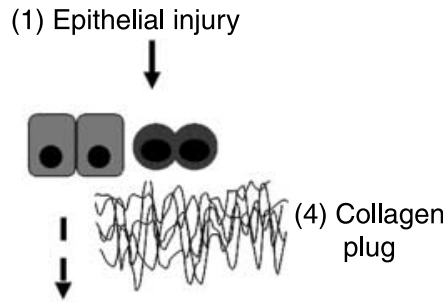

(2) IGF-1

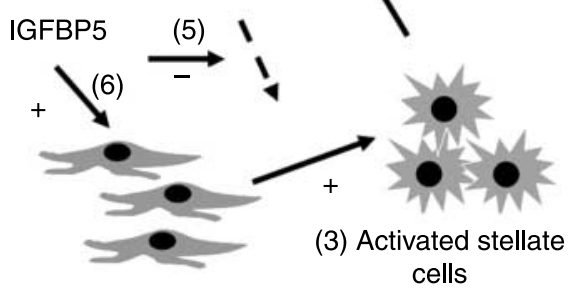

Figure 3 (a) Normal hepatocytes secrete IGF-1 that suppresses (1) stellate cell activation. Stellate cells, in turn, produce (2) HGF that acts as a survival factor for hepatocytes. (b) During (1) toxic injury to hepatocytes, (2) IGF-1 levels decline, facilitating (3) the activation of stellate cells and (4) the deposition of collagen. IGFBP5 may act (5) indirectly to inhibit the actions of IGF-1 or (6) directly upon stellate cells to induce their activation. 
occurs in parallel with the development of hypertrophy of the vascular wall (Capers et al. 1997, Carnell et al. 2007). This occurs in the absence of significant recruitment of macrophages into the media or intima. It has thus been proposed that mechanical strain imparted on the arterial wall as a result of an increase in blood pressure may be an important hypertensive signal. Application of mechanical strain to cultured vascular smooth muscle cells results in an increase in CCL2 expression (Guest et al. 2006). Furthermore, in mice deficient in the CCL2 receptor, hypertension-induced adventitial macrophage infiltration of the arterial wall, and subsequent vascular hypertrophy, was significantly reduced (Maiellaro \& Taylor 2007). These data suggest that there is physiologically relevant linkage between hypertension and macrophage infiltration of the adventitia and that macrophage infiltration of the adventitia is a necessary prerequisite for vascular hypertrophy.

These studies provide compelling evidence for a reconsideration of the initial processes activated during cardiovascular damage and suggest that the mechanisms involved may share considerable similarities with the classic fibrotic diseases.

\section{Is the role of IGFBP5 in fibrosis linked to its role in embryogenesis?}

Although the stimulation of fibroblast activity by IGFBP5 may be unexpected, there is in fact considerable indirect evidence consistent with a role for IGFBP5 in this process in the embryo. Each of the human IGFBP genes is localized to the same chromosomal regions as a specific homeobox $(H O X)$ gene family member (Allander et al. 1997) and HOX genes are well known for their important functions during embryonic development (Krumlauf 1994). IGFBP2 and -5 are linked to the HOXD1 gene family on human chromosome 2 in opposite transcriptional orientations (Allan et al. 2001). The most likely mechanism to explain this linkage is that IGFBP and HOX genes have co-evolved from a single ancestral genetic locus to multiple loci, via the process of chromosomal duplication and translocation. We propose that this linkage is also a functional one since our studies have revealed that IGFBP5 is highly expressed in the apical ectodermal ridge (AER) of the developing mouse embryo (Allan et al. 2001). The AER is a region of specialized pseudostratified epithelium covering the distal edge of the developing limb bud, and the underlying undifferentiated mesenchymal cell population, known as the progress zone. The AER is essential for outgrowth of the limb during development, when the mesodermal cells in the progress zone divide more rapidly. Furthermore, we also showed that IGFBP5 is expressed in the interdigital zone of the developing embryo at sites where programmed cell death occurs and that its expression is altered in the hypodactyly mouse, where digit formation is abnormal (Allan et al. 2000). More recently, a transgenic mouse expressing IGFBP5 in numerous tissues has exhibited major abnormalities and a high incidence of perinatal mortality, adding further evidence for its importance in prenatal development (Salih et al. 2004). Targeted overexpression of IGFBP5 to bone and hair shaft medulla demonstrates its role in both of these processes (Mukherjee \& Rotwein 2007, Park et al. 2007). In addition, IGFBP5 plays an important role in myoblast differentiation (Mukherjee et al. 2008). Based on these reports and our present findings, we speculate that IGFBP5 plays an important role in the development and/or differentiation of mesenchymal tissue and/or cells. This would make its role in fibrosis in the adult highly plausible.

\section{Conclusions}

Fibrosis represents an insidious group of diseases of unknown aetiology making therapies based upon avoidance of the injurious agent impossible at the present time. Thus, the downstream responses involved in the fibrotic cascade itself appear more likely to yield therapeutic targets/strategies. Thus far, anti-inflammatory approaches have failed to provide benefits and so interest has focussed upon TGFB1 as a major inducer of the fibrotic process. Neutralization of TGFB1 actions is a central theme for the inhibition of a number of tissue repair processes including, in particular, scar formation. IGFBP5 may, by analogy, be a target for this strategy. If the process of senescence is central to disease progression, then 'anti-ageing' strategies may be appropriate. There are likely to be many different diseases in which replicative ageing due to excess telomere shortening contributes to tissue-specific or cell-specific disease. For these pathologic processes, rejuvenating cells by increasing telomere lengths may be beneficial. The ability to express telomerase, producing cells with long telomeres and an extended lifespan, has already been achieved. Several reports have suggested that small molecule activators of telomerase can extend the lifespan of lymphocytes, and such molecules might also work with haematopoietic stem cells (Effros 2007). Treatment of pulmonary fibrosis may present an especially difficult clinical challenge because fibrosis of the lung parenchyma is generally considered an end-stage manifestation of an irreversible pathologic process. For this reason, effective treatment of pulmonary fibrosis due to telomerase insufficiency may require early recognition of preclinical disease, modification of environmental exposures and strategies for early intervention with telomerase activation. Biomarkers of the disease state are clearly one way of identifying the preclinical state and studies to evaluate the utility of some of the principal molecules involved in the fibrotic response may prove to be of value in this respect.

Although a wide range of molecules are involved in the twoway communication between the ectoderm and mesoderm (subsequently between epithelium and mesenchyme), evidence for a specific, central role for IGFBP5, when homeostatic mechanisms are perturbed by injury such as physical trauma, infection or cellular stress, is increasingly compelling. IGFBP5 is produced by epithelial cells as part of a suicide pathway at the end of the functional life of the mammary epithelium, and it is secreted and therefore capable of activating fibroblasts involved in tissue reparation. 
It activates a major protease, tPA, generating plasmin which is involved both in the MMP cascade resulting in cellular migration and in the activation of TGFB1. IGFBP5 also interacts with several matricellular proteins that are activated during the response to injury. It remains to be seen whether IGFBP5 is produced under a wide variety of cellular insults, but its association with atherosclerotic plaques (Kim et al. 2007) links it with oxidative stress, and its activation in hypoxia of the brain (O'Donnell et al. 2002) suggests that it may well be a central player in a primitive response to epithelial injury, which may have developed out of its embryonic role as a molecule involved in the epithelial instruction of the underlying mesoderm. Its role in the process of senescence and the evidence for a role of the IGF-axis in longevity means that IGFBP5 has been implicated in every step of the fibrotic response, making it worthy of serious consideration as a therapeutic target for the treatment of fibrotic diseases.

\section{Declaration of interest}

The authors declare that there is no conflict of interest that could be perceived as prejudicing the impartiality of the research reported.

\section{Funding}

We would like to thank the Scottish Government Rural and Environment Research and Analysis Directorate (RERAD) for their support of our research programme.

\section{References}

Abreu JG, Ketpura NI, Reversade B \& De Robertis EM 2002 Connectivetissue growth factor (CTGF) modulates cell signalling by BMP and TGF- $\beta$ Nature Cell Biology 4 599-604.

Allan GJ, Flint DJ, Darling SM, Geh J \& Patel K 2000 Altered expression of insulin-like growth factor-1 and insulin like growth factor binding proteins2 and 5 in the mouse mutant Hypodactyly (Hd) correlates with sites of apoptotic activity. Anatomica Embryologica 202 1-11.

Allan GJ, Flint DJ \& Patel K 2001 Insulin-like growth factor axis during embryonic development. Reproduction 122 31-39.

Allander SV, Coleman M, Luthman H \& Powell DR 1997 Chicken insulinlike growth factor binding protein (IGFBP)-5: conservation of IGFBP-5 structure and expression during evolution. Comparative Biochemistry and Physiology. Part B, Biochemistry and Molecular Biology 116 477-483.

Amaar YG, Thompson GR, Linkhart TA, Chen ST, Baylink DJ \& Mohan S 2002 Insulin-like growth factor-binding protein 5 (IGFBP-5) interacts with a four and a half LIM protein 2 (FHL2). Journal of Biological Chemistry 277 12053-12060.

Amaar YG, Baylink DJ \& Mohan S 2005 Ras-association domain family 1 protein, RASSF1C, is an IGFBP-5 binding partner and a potential regulator of osteoblast cell proliferation. Journal of Bone and Mineral Research $201430-1439$

Andress DL 1998 Insulin-like growth factor-binding protein-5 (IGFBP-5) stimulates phosphorylation of the IGFBP-5 receptor. American Journal of Physiology 274 E744-E750.

Arai T, Arai A, Busby WH Jr \& Clemmons DR 1994 Glycosaminoglycans inhibit degradation of insulin-like growth factor- binding protein-5. Endocrinology 135 2358-2363.

Beattie J, Allan GJ, Lochrie JD \& Flint DJ 2006 Insulin-like growth factorbinding protein-5 (IGFBP-5): a critical member of the IGF axis. Biochemical Journal 395 1-19.
Beausejour CM, Krtolica A, Galimi F, Narita M, Lowe SW, Yaswen P \& Campisi J 2003 Reversal of human cellular senescence: roles of the p53 and p16 pathways. EMBO Journal 22 4212-4222.

Best PJ, Hasdai D, Sangiorgi G, Schwartz RS, Holmes DR Jr, Simari RD \& Lerman A 1999 Apoptosis. Basic concepts and implications in coronary artery disease. Arteriosclerosis, Thrombosis, and Vascular Biology 19 14-22.

Bogatkevich GS, Gustilo E, Oates JC, Feghali-Bostwick C, Harley RA, Silver RM \& Ludwicka-Bradley A 2005 Distinct PKC isoforms mediate cell survival and DNA synthesis in thrombin-induced myofibroblasts. American Journal of Physiology. Lung Cellular and Molecular Physiology 288 L190-L201.

Campbell PG \& Andress DL 1997 Insulin-like growth factor (IGF)-binding protein-5-(201-218) region regulates hydroxyapatite and IGF-1 binding. American Journal of Physiology 273 E1005-E1013.

Campisi J 2005 Senescent cells, tumor suppression, and organismal aging: good citizens, bad neighbors. Cell 120 513-522.

Capers QT, Alexander RW, Lou P, De Leon H, Wilcox JN, Ishizaka N, Howard AB \& Taylor WR 1997 Monocyte chemoattractant protein-1 expression in aortic tissues of hypertensive rats. Hypertension 30 1397-1402.

Carnell PH, Vito RP \& Taylor WR 2007 Characterizing intramural stress and inflammation in hypertensive arterial bifurcations. Biomechanics and Modeling in Mechanobiology 6 409-421.

Chakravarthy MV, Abraha TW, Schwartz RJ, Fiorotto ML \& Booth FW 2000 Insulin-like growth factor-I extends in vitro replicative life span of skeletal muscle satellite cells by enhancing G1/S cell cycle progression via the activation of phosphatidylinositol $3^{\prime}$-kinase/Akt signaling pathway. Journal of Biological Chemistry 275 35942-35952.

Chambers RC 2008 Procoagulant signalling mechanisms in lung inflammation and fibrosis: novel opportunities for pharmacological intervention? British Journal of Pharmacology 153 (Suppl 1) S367-S378.

Chambers RC, Leoni P, Blanc-Brude OP, Wembridge DE \& Laurent GJ 2000 Thrombin is a potent inducer of connective tissue growth factor production via proteolytic activation of protease-activated receptor-1. Journal of Biological Chemistry 275 35584-35591.

Clemmons DR, Busby WH, Arai T, Nam TJ, Clarke JB, Jones JI \& Ankrapp DK 1995 Role of insulin-like growth factor binding proteins in the control of IGF actions. Progress in Growth Factor Research 6 357-366.

Costner MI \& Jacobe H 2000 Dermatopathology of connective tissue diseases. Advances in Dermatology 16 323-359 (discussion 360).

Deng X, Mercer PF, Scotton CJ, Gilchrist A \& Chambers RC 2008 Thrombin induces fibroblast CCL2/JE production and release via coupling of PAR 1 to G $\alpha$ q and cooperation between ERK1/2 and Rho kinase signaling pathways. Molecular Biology of the Cell 19 2520-2533.

Dimri GP, Lee X, Basile G, Acosta M, Scott G, Roskelley C, Medrano EE, Linskens M, Rubelj I, Pereira-Smith O et al. 1995 A biomarker that identifies senescent human cells in culture and in aging skin in vivo. PNAS $929363-9367$

Effros RB 2007 Telomerase induction in T cells: a cure for aging and disease? Experimental Gerontology 42 416-420.

Eyden B 2001 The myofibroblast: an assessment of controversial issues and a definition useful in diagnosis and research. Ultrastructural Pathology 25 39-50.

Feghali CA \& Wright TM 1999 Identification of multiple, differentially expressed messenger RNAs in dermal fibroblasts from patients with systemic sclerosis. Arthritis and Rheumatism 42 1451-1457.

Firth SM \& Baxter RC 1995 The role of glycosylation in the action of IGFBP-3. Progress in Growth Factor Research 6 223-229.

Flint DJ, Tonner E \& Allan GJ 2000 Insulin-like growth factor binding proteins: IGF-dependent and -independent effects in the mammary gland. Journal of Mammary Gland Biology and Neoplasia 5 65-73.

Garcia CK, Wright WE \& Shay JW 2007 Human diseases of telomerase dysfunction: insights into tissue aging. Nucleic Acids Research 35 7406-7416.

Gross TJ \& Hunninghake GW 2001 Idiopathic pulmonary fibrosis. New England Journal of Medicine 345 517-525.

Guenette RS \& Tenniswood M 1994 The role of growth factors in the suppression of active cell death in the prostate: an hypothesis. Biochemistry and Cell Biology 72 553-559.

Guest TM, Vlastos G, Alameddine FM \& Taylor WR 2006 Mechanoregulation of monocyte chemoattractant protein-1 expression in rat vascular smooth muscle cells. Antioxidants and Redox Signaling 8 1461-1471. 
Hampel B, Fortschegger K, Ressler S, Chang MW, Unterluggauer H, Breitwieser A, Sommergruber W, Fitzky B, Lepperdinger G, Jansen-Durr P et al. 2006 Increased expression of extracellular proteins as a hallmark of human endothelial cell in vitro senescence. Experimental Gerontology 41 474-481.

Hayflick L \& Moorhead PS 1961 The serial cultivation of human diploid cell strains. Experimental Cell Research 25 585-621.

Highland KB \& Silver RM 2005 New developments in scleroderma interstitial lung disease. Current Opinions in Rheumatology 17 737-745.

Holzenberger M 2004 The GH/IGF-1 axis and longevity. European Journal of Endocrinology 151 (Suppl 1) S23-S27.

Holzenberger M, Dupont J, Ducos B, Leneuve P, Geloen A, Even PC, Cervera P \& Le Bouc Y 2003 IGF-1 receptor regulates lifespan and resistance to oxidative stress in mice. Nature 421 182-187.

Howell DC, Goldsack NR, Marshall RP, McAnulty RJ, Starke R, Purdy G, Laurent GJ \& Chambers RC 2001 Direct thrombin inhibition reduces lung collagen, accumulation, and connective tissue growth factor mRNA levels in bleomycin-induced pulmonary fibrosis. American Journal of Pathology 159 1383-1395.

Howell DC, Johns RH, Lasky JA, Shan B, Scotton CJ, Laurent GJ \& Chambers RC 2005 Absence of proteinase-activated receptor-1 signaling affords protection from bleomycin-induced lung inflammation and fibrosis. American Journal of Pathology 166 1353-1365.

Inoki I, Shiomi T, Hashimoto G, Enomoto H, Nakamura H, Makino K, Ikeda E, Takata S, Kobayashi K \& Okada Y 2002 Connective tissue growth factor binds vascular endothelial growth factor (VEGF) and inhibits VEGFinduced angiogenesis. FASEB Journal 16 219-221.

Jabs A, Okamoto E, Vinten-Johansen J, Bauriedel G \& Wilcox JN 2007 Sequential patterns of chemokine- and chemokine receptor-synthesis following vessel wall injury in porcine coronary arteries. Atherosclerosis 192 75-84.

Jacobs JJ \& de Lange T 2004 Significant role for p16INK4a in p53independent telomere-directed senescence. Current Biology 14 2302-2308.

Jenkins RG, Su X, Su G, Scotton CJ, Camerer E, Laurent GJ, Davis GE, Chambers RC, Matthay MA \& Sheppard D 2006 Ligation of proteaseactivated receptor 1 enhances alpha(v)beta6 integrin-dependent TGF- $\beta$ activation and promotes acute lung injury. Journal of Clinical Investigation 116 1606-1614.

Jones JI, Gockerman A, Busby WH Jr, Camacho-Hubner C \& Clemmons DR 1993 Extracellular matrix contains insulin-like growth factor binding protein-5: potentiation of the effects of IGF-1. Journal of Cell Biology 121 679-687.

Jurgeit A, Berlato C, Obrist P, Ploner C, Massoner P, Schmolzer J, Haffner MC, Klocker H, Huber LA, Geley S et al. 2007 Insulin-like growth factorbinding protein-5 enters vesicular structures but not the nucleus. Traffic 8 1815-1828.

Kenyon C 2001 A conserved regulatory system for aging. Cell 105 165-168.

Kim WH, Matsumoto K, Bessho K \& Nakamura T 2005 Growth inhibition and apoptosis in liver myofibroblasts promoted by hepatocyte growth factor leads to resolution from liver cirrhosis. American Journal of Pathology 166 1017-1028.

Kim KS, Seu YB, Baek SH, Kim MJ, Kim KJ, Kim JH \& Kim JR 2007 Induction of cellular senescence by insulin-like growth factor binding protein-5 through a p53-dependent mechanism. Molecular Biology of the Cell 18 4543-4552.

Kirk TZ, Mark ME, Chua CC, Chua BH \& Mayes MD 1995 Myofibroblasts from scleroderma skin synthesize elevated levels of collagen and tissue inhibitor of metalloproteinase (TIMP-1) with two forms of TIMP-1. Journal of Biological Chemistry 270 3423-3428.

Kissin E \& Korn JH 2002 Apoptosis and myofibroblasts in the pathogenesis of systemic sclerosis. Current Rheumatology Reports 4 129-135.

Krumlauf R 1994 Hox genes in vertebrate development. Cell 78 191-201.

Leask A \& Abraham DJ 2004 TGF-beta signaling and the fibrotic response. FASEB Journal 18 816-827.

LeRoy EC 1992 A brief overview of the pathogenesis of scleroderma (systemic sclerosis). Annals of Rheumatic Disease 51 286-288.

Lin Y, Xie WF, Chen YX, Zhang X, Zeng X, Qiang H, Chen WZ, Yang XJ, Han ZG \& Zhang ZB 2005 Treatment of experimental hepatic fibrosis by combinational delivery of urokinase-type plasminogen activator and hepatocyte growth factor genes. Liver International 25 796-807.
Liu B, Weinzimer SA, Gibson TB, Mascarenhas D \& Cohen P 2003 Type I alpha collagen is an IGFBP-3 binding protein. Growth Hormone and IGF Research 13 89-97.

Longo VD \& Finch CE 2003 Evolutionary medicine: from dwarf model systems to healthy centenarians? Science 299 1342-1346.

Maiellaro K \& Taylor WR 2007 The role of the adventitia in vascular inflammation. Cardiovascular Research 75 640-648.

Mayes MD, Lacey JV Jr, Beebe-Dimmer J, Gillespie BW, Cooper B, Laing TJ \& Schottenfeld D 2003 Prevalence, incidence, survival, and disease characteristics of systemic sclerosis in a large US population. Arthritis and Rheumatism 48 2246-2255.

Mohan S \& Baylink DJ 2002 IGF-binding proteins are multifunctional and act via IGF-dependent and -independent mechanisms. Journal of Endocrinology 175 19-31.

Mohan S, Thompson GR, Amaar YG, Hathaway G, Tschesche H \& Baylink DJ 2002 ADAM-9 is an insulin-like growth factor binding protein-5 protease produced and secreted by human osteoblasts. Biochemistry $\mathbf{4 1}$ 15394-15403.

Morales TI 1997 The role and content of endogenous insulin-like growth factor-binding proteins in bovine articular cartilage. Archives of Biochemistry and Biophysics 343 164-172.

Mukherjee A \& Rotwein P 2007 Insulin-like growth factor binding protein-5 in osteogenesis: facilitator or inhibitor? Growth Hormone and IGF Research 17 179-185.

Mukherjee A, Wilson EM \& Rotwein P 2008 Insulin-like growth factor (IGF) binding protein-5 blocks skeletal muscle differentiation by inhibiting IGF actions. Molecular Endocrinology 22 206-215.

Nam TJ, Busby WH Jr \& Clemmons DR 1994 Human fibroblasts secrete a serine protease that cleaves insulin-like growth factor-binding protein-5. Endocrinology 135 1385-1391.

Nam TJ, Busby WH Jr, Rees C \& Clemmons DR 2000 Thrombospondin and osteopontin bind to insulin-like growth factor (IGF)-binding protein-5 leading to an alteration in IGF-1-stimulated cell growth. Endocrinology 141 1100-1106.

Nguyen TQ \& Goldschmeding R 2008 Bone morphogenetic protein-7 and connective tissue growth factor: novel targets for treatment of renal fibrosis? Pharmacological Research 25 2416-2426.

Ning Y, Hoang B, Schuller AG, Cominski TP, Hsu MS, Wood TL \& Pintar JE 2007 Delayed mammary gland involution in mice with mutation of the insulin-like growth factor binding protein 5 gene. Endocrinology 148 2138-2147.

O'Donnell SL, Frederick TJ, Krady JK, Vannucci SJ \& Wood TL 2002 IGF-1 and microglia/macrophage proliferation in the ischemic mouse brain. Glia 39 85-97.

Ohba T, McDonald JK, Silver RM, Strange C, LeRoy EC \& Ludwicka A 1994 Scleroderma bronchoalveolar lavage fluid contains thrombin, a mediator of human lung fibroblast proliferation via induction of plateletderived growth factor alpha-receptor. American Journal of Respiratory Cell and Molecular Biology 10 405-412.

Okamoto E, Couse T, De Leon H, Vinten-Johansen J, Goodman RB, Scott NA \& Wilcox JN 2001 Perivascular inflammation after balloon angioplasty of porcine coronary arteries. Circulation 104 2228-2235.

Pagano PJ \& Gutterman DD 2007 The adventitia: the outs and ins of vascular disease. Cardiovascular Research 75 636-639.

Park JI, Jeong JS, Han JY, Kim DI, Gao YH, Park SC, Rodgers GP \& Kim IH 2000 Hydroxyurea induces a senescence-like change of K562 human erythroleukemia cell. Journal of Cancer Research and Clinical Oncology 126 455-460.

Park JY, Park YH, Shin DH \& Oh SH 2007 Insulin-like growth factor binding protein (IGFBP)-mediated hair cell survival on the mouse utricle exposed to neomycin: the roles of IGFBP-4 and IGFBP-5. Acta Oto-Laryngologica $55822-29$.

Pilewski JM, Liu L, Henry AC, Knauer AV \& Feghali-Bostwick CA 2005 Insulin-like growth factor binding proteins 3 and 5 are overexpressed in idiopathic pulmonary fibrosis and contribute to extracellular matrix deposition. American Journal of Pathology 166 399-407. 
Raghu G, Weycker D, Edelsberg J, Bradford WZ \& Oster G 2006 Incidence and prevalence of idiopathic pulmonary fibrosis. American Journal of Respiratory and Critical Care Medicine 174 810-816.

Salih DA, Tripathi G, Holding C, Szestak TA, Gonzalez MI, Carter EJ, Cobb LJ, Eisemann JE \& Pell JM 2004 Insulin-like growth factor-binding protein 5 (Igfbp5) compromises survival, growth, muscle development, and fertility in mice. PNAS 101 4314-4319.

Sanz S, Pucilowska JB, Liu S, Rodriguez-Ortigosa CM, Lund PK, Brenner DA, Fuller CR, Simmons JG, Pardo A, Martinez-Chantar ML et al. 2005 Expression of insulin-like growth factor I by activated hepatic stellate cells reduces fibrogenesis and enhances regeneration after liver injury. Gut 54 134-141.

Sappino AP, Masouye I, Saurat JH \& Gabbiani G 1990 Smooth muscle differentiation in scleroderma fibroblastic cells. American Journal of Pathology 137 585-591.

Schedlich LJ, Young TF, Firth SM \& Baxter RC 1998 Insulin-like growth factor-binding protein (IGFBP)-3 and IGFBP-5 share a common nuclear transport pathway in T47D human breast carcinoma cells. Journal of Biological Chemistry 273 18347-18352.

Schneider MR, Wolf E, Hoeflich A \& Lahm H 2002 IGF-binding protein-5: flexible player in the IGF system and effector on its own. Journal of Endocrinology 172 423-440.

Scott NA, Cipolla GD, Ross CE, Dunn B, Martin FH, Simonet L \& Wilcox JN 1996 Identification of a potential role for the adventitia in vascular lesion formation after balloon overstretch injury of porcine coronary arteries. Circulation 93 2178-2187.

Scotton CJ \& Chambers RC 2007 Molecular targets in pulmonary fibrosis: the myofibroblast in focus. Chest 132 1311-1321.

Selman M \& Pardo A 2006 Role of epithelial cells in idiopathic pulmonary fibrosis: from innocent targets to serial killers. Proceedings of the American Thoracic Society 3 364-372.

Serrano M, Lin AW, McCurrach ME, Beach D \& Lowe SW 1997 Oncogenic ras provokes premature cell senescence associated with accumulation of p53 and p16INK4a. Cell 88 593-602.

Shimokawa I, Higami Y, Utsuyama M, Tuchiya T, Komatsu T, Chiba T \& Yamaza H 2002 Life span extension by reduction in growth hormoneinsulin-like growth factor-1 axis in a transgenic rat model. American Journal of Pathology 160 2259-2265.

Shimokawa I, Higami Y, Tsuchiya T, Otani H, Komatsu T, Chiba T \& Yamaza H 2003 Life span extension by reduction of the growth hormone-insulinlike growth factor-1 axis: relation to caloric restriction. FASEB Journal 17 1108-1109.

Smith JR \& Pereira-Smith OM 1996 Replicative senescence: implications for in vivo aging and tumor suppression. Science 273 63-67.

Sorrell AM, Shand JH, Tonner E, Gamberoni M, Accorsi PA, Beattie J, Allan GJ \& Flint DJ 2006 Insulin-like growth factor-binding protein-5 activates plasminogen by interaction with tissue plasminogen activator, independently of its ability to bind to plasminogen activator inhibitor-1, insulin-like growth factor-I, or heparin. Journal of Biological Chemistry $\mathbf{2 8 1}$ 10883-10889.

Steen V 2007 Scleroderma renal crisis. Indian Journal of Medical Sciences $\mathbf{6 1}$ 71-72.

Takehara K 2003 Hypothesis: pathogenesis of systemic sclerosis. Journal of Rheumatology 30 755-759.

Tonner E, Barber MC, Allan GJ, Beattie J, Webster J, Whitelaw CB \& Flint DJ 2002 Insulin-like growth factor binding protein-5 (IGFBP-5) induces premature cell death in the mammary glands of transgenic mice. Development 129 4547-4557.

Tyner SD, Venkatachalam S, Choi J, Jones S, Ghebranious N, Igelmann H, Lu X, Soron G, Cooper B, Brayton C et al. 2002 p53 mutant mice that display early ageing-associated phenotypes. Nature 415 45-53.

Wagner M, Hampel B, Bernhard D, Hala M, Zwerschke W \& Jansen-Durr P 2001 Replicative senescence of human endothelial cells in vitro involves G1 arrest, polyploidization and senescence-associated apoptosis. Experimental Gerontology 36 1327-1347.

Willis BC, Liebler JM, Luby-Phelps K, Nicholson AG, Crandall ED, du Bois RM \& Borok Z 2005 Induction of epithelial-mesenchymal transition in alveolar epithelial cells by transforming growth factor-beta1: potential role in idiopathic pulmonary fibrosis. American Journal of Pathology 166 1321-1332.

Yasuoka H, Jukic DM, Zhou Z, Choi AM \& Feghali-Bostwick CA 2006 a Insulin-like growth factor binding protein 5 induces skin fibrosis: a novel murine model for dermal fibrosis. Arthritis and Rheumatism 54 3001-3010.

Yasuoka H, Zhou Z, Pilewski JM, Oury TD, Choi AM \& Feghali-Bostwick CA $2006 b$ Insulin-like growth factor-binding protein-5 induces pulmonary fibrosis and triggers mononuclear cellular infiltration. American Journal of Pathology 169 1633-1642.

Yoon IK, Kim HK, Kim YK, Song IH, Kim W, Kim S, Baek SH, Kim JH \& Kim JR 2004 Exploration of replicative senescence-associated genes in human dermal fibroblasts by cDNA microarray technology. Experimental Gerontology 39 1369-1378.

Zhu J, Woods D, McMahon M \& Bishop JM 1998 Senescence of human fibroblasts induced by oncogenic Raf. Genes and Development 12 2997-3007.

Received in final form 31 July 2008

Accepted 1 August 2008

Made available online as an Accepted Preprint 1 August 2008 